\title{
Health literacy and social capital: What role for adult literacy partnerships and pedagogy?
}

\author{
Stephen Black, Jo Balatti and Ian Falk
}

This paper makes the case for adult literacy (including numeracy) practitioners to play a greater role in health literacy initiatives in Australia. The paper draws on data from a national research project that investigated adult literacy partnerships and pedagogy viewed from a social capital perspective. The primary purpose of the project was to produce guidelines on how to deliver integrated adult literacy and numeracy programmes using a social capital approach. Prior experience of partnerships was explored through a review of the literature and an environmental scan of adult literacy providers using an email survey and follow-up interviews. An in-depth case study of a health literacy partnership was trialled using action research. Partnerships between adult literacy and health organisations in Australia were found to be largely ad hoc and rarely documented. To enable sustainable health literacy programmes, partnerships are needed across the three interlinked organisational levels - micro, meso and macro, and in particular the latter, which is currently almost completely absent. The conceptual frameworks outlined for health literacy partnerships and social capital pedagogy in this paper are new and potentially of value to policy makers, researchers and practitioners in the fields of health and literacy.

Keywords: health literacy, adult literacy, partnerships, social capital, empowerment, pedagogy

\section{Introduction}

This paper focuses on health literacy in Australia, and in particular, the role of adult literacy practitioners (in this paper we include numeracy within the broader use of the term literacy). We indicate that while research and practice in the area of health literacy have been burgeoning for the past couple of decades both overseas and in Australia, one element lacking in Australia is the role of adult literacy practitioners. To date, health literacy in Australia has been predominantly the concern of health specialists (see for example, Nutbeam et al. 1993; Nutbeam 1999; Green, Lo Bianco, and Wyn 2007; Keleher and Hagger 2007; Peerson and Saunders 2009), with voices in the adult literacy sector virtually silent beyond claims about the need for partnerships with the health sector (e.g. Figgis 2004; Wickert and McGuirk 2005; Hartley and Horne 2006; Black and Yasukawa 2010). This paper makes a case for a greater role by adult literacy practitioners, explaining how this can be achieved through a social capital approach, and leading potentially to improved health outcomes for individuals and communities.

Data for the paper are drawn mainly from a study funded by the National Centre for Vocational Education Research of adult literacy partnerships and pedagogy involving a number of sectors including health (Balatti, Black and Falk 2009). The study represented one of the very few Australian studies to have investigated the role of adult literacy practitioners in health literacy initiatives. It was undertaken at a time when there was (and remains) a potential catalyst for increased action in health literacy - the publication of the first national health literacy survey (Australian Bureau of Statistics 2008), produced in conjunction with the adult literacy and life skills survey (Australian Bureau of Statistics 2007). The health literacy survey indicated that only $41 \%$ of the adult population were assessed as 'having adequate or better health literacy skills' based on those scoring at level 3 or above on the five point scale used by the OECD to 
measure literacy levels and well-being (see OECD/Statistics Canada 2005). Widespread publicity about chronic health problems in Australia resulting from largely preventable lifestyle factors also provided a potential catalyst for health literacy initiatives, including news of a national type 2 diabetes 'epidemic' (Diabetes Australia 2007), and Australia's growing obesity problem described as a future 'fat bomb' (Stewart et al. 2008). Investigating how adult literacy practitioners could partner with the health sector as one additional element in attempts to better understand and address largely preventable national health problems appeared to be long overdue. Further, as we indicate in the literature review, social capital can be seen to play a key role in the health and well-being of individuals and communities, and adult literacy practitioners, in partnership with health professionals may be well situated to develop and build on these social capital resources.

A few comments need to be made at this point regarding some key terms and definitions in this paper, though a discussion of what is meant by health literacy is addressed later in the literature review. By partnership we mean 'a mutually beneficial and well-defined relationship entered into by two or more organisations to achieve a common goal' (Mattessich, Murray-Close and Monsey 2004, 4). By pedagogy we mean what teachers do in the learning context, for example, in the classroom, workplace or community centre. It refers to the design of the learning experiences and includes teaching/learning strategies used and the learning environment created (Balatti, Black and Falk 2009, 13). By social capital we mean 'networks, together with shared norms, values and understandings which facilitate cooperation within and amongst groups' (Australian Bureau of Statistics 2004, 5).

\section{Literature review}

This paper builds on research from a number of different yet related areas. They include the literature on health literacy studies, and also various adult literacy studies, in particular studies of 'integrated' literacy, which to date have mainly featured in research in the fields of workplace programmes and vocational education and training. An understanding of social capital is also integral, and partnerships across organisations at the macro, meso and micro levels can be seen as a key element of a social capital perspective.

\section{Health literacy and adult literacy practitioners}

Health literacy is a contested concept. For the most part health literacy studies, and in particular many in the United States, have focused on people's ability to read and comprehend health messages in clinical settings. This conceptualisation of health literacy has been termed 'medical literacy' (Peerson and Saunders 2009), focusing on 'risk factors' (Nutbeam 2008) in which the aim is usually to simplify health messages in order to make them more readable for people considered to be in a risk category. This approach, however, is often far from straightforward, and its effectiveness has been called into question because it fails to take into account various linguistic and cultural variables (Zarcadoolas 2010). It fits largely within a deficit approach to health literacy, focusing on individuals and communities who lack particular skills, and then looking for ways of addressing the deficit, most often, as indicated, through simplifying the way the health messages are presented. 
An alternative conceptualisation sees health literacy more in terms of people's well-being in everyday life contexts. Nutbeam (2008), for example, refers to this form of health literacy as 'an asset', in which people and communities are empowered to make appropriate health decisions and thus improve and manage their own health. It relates especially to health promotion studies and preventive health measures, taking into account the broader social, cultural and environmental determinants of health. It is a more critical, dynamic

conceptualisation, though as some researchers point out, knowing about health does not necessarily equate with people's motivation to act on that knowledge (Peerson and Sanders 2009). This alternative understanding of health literacy, which incorporates individual and community empowerment to make informed choices to reduce health risks and increase quality of life, is the one that frames this current study.

To date, health literacy studies involving various programme interventions have featured most strongly in the United States (e.g. Nielsen-Bohlman, Panzar and Kindig 2004), and also in Canada (e.g. Rootman and Gordon-El-Bihbety 2008) and parts of Europe (e.g. Kickbusch, Wait and Maag 2005). In these countries and regions there are also examples of strong links between the adult literacy and health sectors. In the United States, this has been evident since the 1990s (e.g. Sissel and Hohn 1996), and includes strong local community programmes based on health empowerment models (Hohn 1998). Almost a decade ago these links between adult literacy and the health sector were described as 'a maturing partnership' (Rudd 2002), and a wide range of partnerships are current (Diehl 2011). Canada also features such partnerships (Shohet 2004), as does the UK with its 'Skilled for health' initiatives (The Tavistock Institute 2009). In Australia, by contrast, such documented partnerships are rare, leading to one small partnership between health and adult literacy practitioners being described metaphorically as 'a first date' (Black 2012).

In the above programs, when adult literacy practitioners work collaboratively with the health sector they are usually required to adopt an integrated concept of literacy. That is, the primary objective of a health literacy programme is to improve health not literacy outcomes, though literacy skills are addressed 'as interrelated elements of the same process'

(Courtenay and Mawer 1995, 2). Australian adult literacy practitioners have for many years adopted 'integrated' literacy approaches in areas such as workplace literacy (McKenna and Fitzpatrick 2005), and providing support for students undertaking vocational education and training courses (Black and Yasukawa 2011). At one stage there were claims that adult literacy practitioners in Australia were leading the world in such integrated approaches (Australian National Training Authority 2003, 3). In providing integrated literacy support in vocational education courses, recent research has indicated that most provision fits within a deficit approach focussing on students with 'problems'. Suggested as more effective integrated programmes are those in which the literacy teacher shares greater responsibility with disciplinary teachers for student outcomes, and where teachers draw on the strengths of students rather than their deficits (Black and Yasukawa 2011). Apart from workplace and vocational education programmes, however, the adult literacy field in Australia has been slow to respond to integrated literacy approaches in other sectors, and this seems to be due largely to a lack of policy direction and sustainable funding (Wickert and McGuirk 2005).

\section{Partnerships and social capital}


In both the health and adult literacy sectors there is currently a push for partnerships as part of a trend to 'linked-up' or 'whole-of-government' approaches to addressing social policy issues. In health promotion the push for such partnerships and alliances has been going on internationally for more than a decade (e.g. Gillies 1998), and no doubt encouraged by the required actions of the Bangkok Charter for Health Promotion which stipulated the need for partnering and building alliances (World Health Organisation 2005). There have been major shifts in health discourses in recent decades from clinical and curative measures to the growing recognition of the broader social, economic and environmental determinants of health (e.g. Wilkinson and Marmot 2003; Keleher and Murphy 2004; World Health Organisation 2008), leading to the call to cross the boundaries of different policy sectors and break down previous 'silo' approaches to health. The title of one recent Australian health study begins with the call 'Partner or perish' (Boyer et al. 2010).

The adult literacy sector in Australia is relatively new to the promotion of partnerships, but in recent years cross sectoral partnerships, community capacity building and notions of 'integrated' and 'social practice' understandings of literacy have been promoted strongly in some national research reports (e.g. Figgis 2004; Wickert and McGuirk 2005; Hartley and Horne 2006; Balatti, Black and Falk 2009). One area where adult literacy practitioners have partnered with the health sector is in the training of health workers, especially in areas such as aged care (e.g. Booth et al. 2005). Cross sector partnerships have also been promoted strongly in the more general vocational education and training sector in recent years (e.g. Allison et al. 2006).

Linked to the push for partnerships is the concept of social capital, which we view in this paper as comprising networks and relations between people within groups (Australian Bureau of Statistics 2004, 5). While social capital is also a contested concept, in this paper we view it primarily as a resource, highlighting the role of networks that lead to economic or social gain for either groups or individuals. Portes $(1998,3)$ noted that 'studies have stretched the concept from a property of individuals and families to a feature of communities, cities and even nations'. Thus, social capital can be seen as both a private good, that is, an asset owned by individuals, and a public good, that is, an asset owned by a group and beneficial to members of that group. Concepts such as family social capital (Coleman 1990), community social capital (Putnam 1993) and intra-organisational and interorganisational social capital (Leenders and Gabbay 1999) have entered the discourse around social capital in an attempt to define and understand it.

With respect to social capital as a private good, the two-way connections between learning, both formal and informal, and social capital have been the focus of much research (e.g. Coleman 1988; Schuller and Field 1998; Balatti, Black and Falk 2006). The relationship between social capital and human capital has especially attracted the interest of researchers who theorise learning as a social activity. In a discussion of the kinds of social arrangements that best promote lifelong learning, Field and Schuller $(1997,17)$ state:

Social capital ... treats learning not as a matter of individual acquisition of skills and knowledge, but as a function of identifiable social relationships. It also draws attention to the role of norms and values in the motivation to learn as well as in the acquisition of skills, and the deployment of new know-how. 
As well as learning leading to social capital, the learners' existing social capital influences the kind of learning with which they engage and how they engage with it. This relationship has been explored in terms of how the learner's knowledge resources (for example, skills, contacts, know-how) and identity resources (for example, who the learner perceives himself/herself to be, self-confidence) are drawn on or changed as the result of interacting with others (Balatti and Falk 2002).

In this paper, social capital production is investigated in two domains. The first is at the group level, that is, the networks that exist among government, agencies, service providers and community groups that are implicated in health literacy partnerships with adult literacy practitioners. The second domain is at the individual level in which the social capital outcomes experienced by participants in health literacy partnerships are explored. In relation to individuals, social capital outcomes in this paper refer to the changes that programme participants experience in the way they interact with members of their existing networks and also the changes in the types and numbers of networks that they access or of which they become members. Networks refer to any formal or informal groupings of people with which the learners engage, including family, friendship groups, special interest groups, government systems such as health and education, employing bodies, and goods and services providers.

That these social capital outcomes can come about from the interactions that occur in the learning context is clear (Falk, Golding, and Balatti 2000; Balatti, Black, and Falk 2006), but how they come about is complex. One set of factors that affects the nature of social capital outcomes experienced is the existing social, cultural and human capital that participants bring to the learning experience and the resources that participants can draw on in their community. Another is the nature of the teaching that learners experience. Research (e.g. Balatti and Falk 2002; Balatti, Black, and Falk 2006; Balatti and Black 2011) has found that the design of the learning experiences, that is, where, when and how they are offered, by whom, and for whom, affects the quality of the learning experienced, including the kinds of social capital outcomes achieved.

Social capital is increasingly playing a role in both health and adult literacy discourses. For example, at a basic statistical level, the Australian health literacy survey (Australian Bureau of Statistics 2008) indicated that those who participate in groups and organisations, even as nonpaid volunteers, achieve higher health literacy levels than those who do not participate. While there are researchers who see the role of social capital in health as both complex and contested (e.g. Campbell 2001; Szreter and Woolcock 2004), nevertheless it is seen to offer a useful starting point and the space to examine the dynamics involved in the social determinants of health (e.g. Brough et al. 2007). Worldwide, social capital is a burgeoning area of health research (e.g. Kawachi, Subramanian, and Kim 2008).

In the adult literacy field, as we have suggested in this literature review, the authors of this paper have previously documented social capital outcomes from adult literacy courses and how particular pedagogical strategies can help produce these outcomes (Balatti, Black, and Falk 2006). Other researchers have also used social capital constructs for documenting outcomes from adult literacy programmes and have commented on the potential value of social capital for adult learners, including Tett and Maclachlan (2007), and St. Clair (2008). Specifically at the intersection of health learning and adult literacy, Schecter and Lynch (2010) have recently proposed a model for health literacy programmes which focuses on networks of learners as 'communities of practice' (Lave and Wenger 1991; Wenger 1998). 


\section{Research methodology}

The research reported here was approved by the Human Research Ethics Committee at James Cook University, Townsville. The research aimed to provide guidelines on how to deliver adult literacy programmes using a social capital approach, and this paper we report only on the research which focused on health literacy (the original research also included the justice and finance sectors). There were three main phases to the research: Phase one was a review of the research literature to outline health literacy initiatives to date. Phase two was an environmental scan of all known adult literacy providers in one Australian state. This involved an email questionnaire using an existing national database of adult literacy providers (the Reading Writing Hotline database featuring nearly 400 providers listed in the one state surveyed). The aim was to outline the range and types of partnerships, formal and informal, undertaken between adult literacy providers and the health sector, and to locate contact people for more in-depth follow up. Seven programmes were then identified for follow-up, and key players in each of the programmes, mainly the programme managers and practitioners, were interviewed using a semistructured format. All interviews were later transcribed in full. The interviews focused on the following aspects: the types of partnerships, factors that facilitate partnerships, the characteristics of partnerships, any impediments to partnerships, pedagogical strategies, and programme outcomes viewed largely in terms of social capital. In some regional locations these interviews were conducted by phone, and recorded with participants' permission. The seven health literacy partnerships comprised:

- A residential adolescent psychiatric unit and a VET college - individual clients from the unit attended the VET provider's flexibly structured literacy programme, and the VET providers played a role in the case management of clients;

- An inner city medical centre for sex workers and injecting drug users and an Aboriginal education college - a literacy class was held at the centre one afternoon each fortnight (see Black et al. 2012);

- A health care agency employing home carers and a VET college - a literacy class for the carers was held at the agency one afternoon a week;

- A health care agency and a VET college - under the terms of a workplace English language and literacy (WELL) programme, the literacy teacher provided integrated support to carers to support them in undertaking a certificate course in aged care;

- A residential drug and alcohol rehabilitation centre and a VET college - a teacher attended the centre one day each week for mainly individual and small group tuition;

- An Indigenous residential drug and alcohol rehabilitation centre and a VET college - two literacy teachers visited the centre for two afternoons each week for individual and small group tuition.

- An area health service and a VET provider - weekly two-hour 'type 2 diabetes prevention' sessions were delivered to local community groups. Literacy teachers and nutritionists co-delivered the sessions (see Black 2012).

Phase three was a case study using an action research approach. Over a period of six months the case study documented the experiences of a literacy teacher from a VET college and a health 
professional from an area health service who worked together in a community health programme at a centre for Muslim women. Twelve students from a wide range of ages, ethnic backgrounds and formal educational levels participated in the programme, and all were recruited to the programme locally through the network of a Muslim women's association.

The aim of the action research was to trial strategies that could enhance the social capital outcomes of the learners in the programme. The action research followed the reiterative process of planning, action, observation and reflection (e.g. Kemmis and McTaggart 1988) with the adult literacy teacher and the health professional jointly planning sessions, and then reflecting with a researcher in taped sessions at the conclusion of most sessions. Twelve taped sessions were later transcribed in full. The literacy and health practitioners both participated in a workshop on social capital and action research delivered by the researcher prior to the course commencing.

Thus in total, the research data comprised written email questionnaire responses, and interview transcription data from two sources - interviews with personnel in the seven health literacy partnerships, and the reflection sessions from the action research case study.

One of the problems in undertaking a social capital analysis, given the contested nature of the concept of social capital, is the absence of agreed definitions and frameworks. For this study, in order to identify pedagogical practices that can produce social capital outcomes, we used a framework (Table 1) that featured in our previous research (Balatti, Black, and Falk 2006, 17), which in turn was adapted from a study of social capital by the Australian Bureau of Statistics (2004: 4). Thus the indicators of social capital in this study are those found to result in any of the changes listed in the right hand column of Table 1. Not all these indicators were appropriate for the study, given the longer term effects of some of them, but indicators such as trust levels, self efficacy and network types - bonding, bridging and linking ties, were found to be appropriate.

\section{Table 1 Indicators of social capital outcomes (here)}

To classify the interview data in order to assist the identification of pedagogical strategies seen to result in social capital outcomes, all the interview transcript data (from research phase two and three) were examined and coded for evidence of social capital changes based on those indicators identified in the right hand column of Table 1, and then matched with the corresponding pedagogical strategies seen to promote these social capital changes. The coded texts, which could range from single words to a paragraph, were tabulated using Microsoft Excel.

\section{Findings and discussion}

This section focuses on the two key elements of this study - partnerships and pedagogy, with the findings being used to assist the development of some broad guidelines for implementing social practice approaches to health literacy.

\section{Partnerships}

In relation to partnerships involving health and adult literacy organisations, most of the partnerships identified in the email questionnaire involved the federal government's workplace English language and literacy (WELL) programmes. These programmes focus on improving the literacy and numeracy skills of health workers in the interests of up-skilling them, especially in 
light of new professional qualification and organisational accreditation requirements (e.g. in aged care facilities). Beyond WELL programmes, however, relatively few partnerships were found, reinforcing the noted absence of such partnerships in the literature review. The questionnaire and follow-up interviews with the seven partnerships indicated that partnerships, when they are formed, tend to be ad hoc, developing without any policy direction or specific funding allocation. Adult literacy personnel in public VET (i.e. Technical and Further Education - TAFE) organisations featured in most of the identified partnerships, and they usually accessed short term funding for trial or innovative programmes. Very rarely did they receive sustainable funding, and funding matters sometimes required 'imaginative' approaches by committed individuals in VET organisations to keep the programmes running. In the majority of partnerships, it was the adult literacy provider who initiated the partnership. In one case an adult literacy teacher approached the director of a local rehabilitation centre about a possible role in providing literacy support for clients in the centre. She stated: 'I think he was a bit surprised because he hadn't had any contact with TAFE before, particularly knocking on his door offering a free programme'. This example may typify the general trend of health organisations not being aware of the potential role of adult literacy practitioners in health literacy initiatives. In the great majority of the partnerships identified in the research, the teaching and learning took place not in the formal environment of the adult literacy provider, but in health or local community settings.

Overall, based on the trends identified in the questionnaire responses and follow up interviews with the seven partnerships and supported by the literature the research concluded that health literacy partnerships, to be effective, ideally require the following common characteristics:

- $\quad$ sharing a similar value system which may include health organisations, VET providers and community groups valuing the importance of improved literacy for better health and life choices.

- bringing different sets of needed skills and resources to the partnerships, which may include financial, cultural and social capital resources.

- mutual respect amongst the partners, especially at the local level in team-teaching arrangements.

- working as part of a team.

- good communication among partners.

- local flexibility, especially with timetabling, accommodation and resourcing.

- Sustainable funding.

\section{Pedagogy}

As indicated in the methodology section, interview transcript data from the seven partnerships and the action research case study were coded according to social capital outcomes and the pedagogical strategies seen to be responsible for them. The main types of pedagogical strategies identified through this process comprise the main headings in this section: strategies that teachers use to encourage bonding, bridging and linking ties; ways in which teachers build relationships with their learners; strategies that teachers use to encourage peer learning; ways in which teachers engage in collaborative teaching and learning; and ways in which literacy and numeracy learning can be integrated in other training, education or activities. The teacher comments cited in this section were selected from interview data in both phase one and two of the research (the seven partnerships and the case study). 


\section{Developing bonding, bridging and linking ties}

When participants join a programme of learning they become part of a new network of learners, a new community of practice with learning as its focus (Wenger 1998). A social capital perspective to building learning communities draws attention to the connections or ties that teachers would like their learners to develop. Traditionally these ties have been considered either strong or weak (Granovetter 1973), and in the social capital literature they are usually referred to as bonding, bridging and linking ties. Through these ties learners draw on existing knowledge and identity resources and build new resources that can lead to improved socioeconomic wellbeing, including health.

Bonding ties are the strong ties that build cohesion and common purpose within the learning group. These require building trust between the teacher and students and between students. Teachers in this study explained that building trust requires encouraging participants to get to know one another in a non-judgemental climate in which they feel safe sharing their life experiences and making errors as they are learning.

The place of learning can influence bonding ties, as participants may feel more relaxed learning in familiar community contexts, such as a local community health centre, or, as in the case study, a Muslim women's community centre. The physical layout of the pedagogical learning space also affects bonding, with a number of the health literacy programmes in this study featuring participants and teachers seated around one central table, which encouraged inclusive dialogue. The adult literacy teacher in one programme commented that the learning setting 'is more like a social setting around learning rather than a classroom setting where it's the teacher instructing'. On another occasion a teacher described the dialogue in this setting as:

... like the conversation around the family dinner table ... that kind of way that often a theme will run through but people go off on this completely different tangent, and you'll have conversations sort of over the top of each other ...

The learning content needs also to resonate with people's lives, and is usually negotiated with the learners and sufficiently flexible to respond to their changing needs. For example, the health educator in one community programme explained that each session took on 'a life of its own'. Talking initially about stress relief, which the participants agreed they wanted discussed as a programme topic, led to deep and engaging discussions about infidelity, divorce and domestic violence, with a couple of learners revealing very personal details to the group. Other topic tangents involved in-depth discussions about the cross-cultural aspects of bringing up children in Australia, and how to engage with the schools their children attended. This dialogic and negotiated approach to learning content in a relaxed, familiar location, encourages trust building and a sense of belonging in the group. Such an approach is often in marked contrast to many accredited courses undertaken in formal vocational education and training organisations in which teaching and learning are driven primarily by externally prescribed learning outcomes.

Unlike bonding ties, bridging ties are weak ties that that are concerned with learners accessing new networks with groups of people who are different from those of the learners. These ties enable learners to access new ideas, attitudes and beliefs, and potentially empower learners to feel part of a wider community. Pedagogical strategies that encourage bridging ties include group excursions to museums, exhibitions, cultural centres and workplaces. For example, Indigenous participants at an inner city health centre for sex workers and intravenous drug users, were invited on an excursion to the local museum, and also to hear the Dalai Lama on one of his visits 
to the city. The literacy teacher wanted these participants to feel part of the broader society. As she stated:

I want them to think 'I'm not that marginalised by society, I can do this ...' It's like, 'I can pass it off here. No one's looking at me'.

Other pedagogical strategies encouraging bridging ties included inviting guest speakers to the class, and incorporating sessions where participants are required to research external agencies and networks, including various 'mapping exercises' of community health resources - such as gymnasiums, swimming pools, walking groups, and community gardens.

Linking ties facilitate connections between individuals and institutions and systems. In the partnership programmes, and especially where health and literacy practitioners worked closely together, one of the features was explaining how systems worked, where and how to get the most appropriate help. For example, health practitioners in one programme provided the telephone numbers and referral details for local health organisations, including breast screening, dietitians, and diabetes support. Accessing appropriate health websites was another feature.

\section{Teachers building relationships as part of the learners' network}

The nature of the relationship that adult literacy teachers and health practitioners have with their students can contribute to social capital development. Those who are aware of their role in helping to build social capital and thus expand the network associations of their students, usually try to reduce the social distance between themselves and their students. For example, one health practitioner mentioned she deliberately remained seated during sessions because 'I feel like I'm part of the conversation and I think it flows better and promotes that talking, that chatting, conversation ... as opposed to me telling'. Pedagogy for social capital building overall tends to be of a non-didactic kind, in which teachers value the experiences of students and structure their teaching to encourage group work and active student engagement. Teachers are prepared to share their own life experiences, to be part of the discussion groups rather than just monitoring them. In one partnership a teacher volunteered details of her husband's heart valve operation in discussions with a student soon to have tests for a similar medical procedure. Another teacher in a Muslim women's health programme brought her daughter, a university student, along to class to assist with sessions and to accompany the group on excursions.

\section{Opportunities for peer learning}

As a learning community of practice, participants in health literacy partnerships learnt from others in the groups as well as from health 'experts' presenting sessions. The student referred to above with the heart problem, for example, learnt much from his fellow peers with similar experiences. As the teacher explained:

One of the other students said that he had a heart problem and he had to leave his work because of that, and he said 'this is what happened to me ...' And other students said, 'well this is what happened to me, and this is how they checked my heart', and so he actually knew what to expect ...

In a type 2 diabetes prevention programme, the health practitioner could explain what was meant by, and the benefits of, low GI (glycemic index) food, but it was the local community Chinese participants who provided the cultural knowledge and discussion points on the varieties of rice they preferred to consume, and the issues affecting the likelihood of them changing their diet 
patterns. Thus the teacher's role was often to facilitate the learning conditions that encouraged participant discussion and learning, often involving small group work. One literacy teacher explained how in a session on diet, she divided her class into groups of three or four with a large A3 sheet for each group. Participants then discussed their diet and listed what they had eaten the previous day, before coming together and reporting back to the whole class. In this case the content of the lesson was primarily student-driven.

\section{Collaborative delivery}

In a number of partnerships literacy and health practitioners co-delivered programmes. The codelivery models varied, often depending on how the respective practitioners chose to work together, but in several partnerships it was most effective when the co-presenters had an equal, though different role. As a literacy teacher explained, referring to her co-presenting dietitian: 'So, she's like the knowledge, and I kind of structure the class and do the activities like I would normally in an everyday classroom'. Thus the literacy teacher had a role not only in supporting and making explicit the language and literacy aspects, but as an educator, in creating an environment conducive to learning. Two professionals presenting in this way together in the same classroom (or local community hall or medical centre or other community centre) provided participants with the opportunity to actively interact with professionals in ways they do not normally do. Participants could gain confidence in their interactions with professional people, often modelling themselves on the observed interactions between the two co-presenters. Participants were provided with opportunities to develop some familiarity with professional and their organisations and thus gain important links for their present and future health needs.

\section{Integrated literacy learning}

In these collaborative learning environments, literacy (and also language and numeracy) was integrated or embedded in health contexts. In a diabetes prevention programme for example, participants visited a local supermarket, and then later at the community centre they discussed food labels. This required some explicitly taught literacy elements as they grappled with terms and concepts such as ingredients, serving and portion sizes, recommended daily intake, and sugar and sodium levels. In another activity, participants determined their BMI (body mass index), an authentic health-related task which required a degree of measuring and calculating. These concepts were taught in context, or as we have previously noted, 'as interrelated elements of the same process' (Courtenay and Mawer 1995, 2) as participants learnt about health matters. In most cases, as indicated earlier, it meant adult literacy teachers working outside of their regular classroom environment and in local community or health-related settings.

\section{Social capital guidelines for partnerships and pedagogy}

The literature review, questionnaire responses and follow up interviews with partners in health literacy initiatives described an overall picture in which existing partnerships between health and adult literacy organisations in Australia are largely 'ad hoc', and while they appear to be successful as local initiatives, they are nevertheless usually one-off programmes or very limited in duration. We have also indicated the overall characteristics of effective partnerships based on the research findings. To guide the development of future partnerships and to better understand the organisational nature of partnerships and how they might become more sustainable and effective at local and community levels, we provide a heuristic (Figure 1 from Balatti, Black, \& Falk 2009, 33).

\section{Figure 1 Organisational levels for partnerships (here)}


This diagram organises partnerships in terms of three organisational levels, macro, meso and micro, and provides examples of possible stakeholders at each level. The diagram disrupts the commonly held hierarchical construct of locating the 'macro' at the top of the pyramid. Having the micro level i.e. the learners and their teachers, at the top, is a reminder that education interventions only achieve their purpose at the micro level of interaction. It is at the micro level that the learning happens.

Locating the macro level as the foundation of the pyramid serves as a reminder of its importance in sustaining interventions for as long as they are needed. The partnerships at the macro level between government departments and peak organisations produce the policy and the funding that support the efforts at the meso and micro level. Without the support of the macro level, the best efforts of individuals at the meso and micro levels are at risk of being unsustainable.

The horizontal arrows signify the importance of building partnerships within each level. The vertical arrow signifies that good partnerships also have links between the levels as well, for example, policy makers at the macro level have ongoing consultation with and provide funding for implementers of policy and the intended beneficiaries. The final element of the diagram is the overlay of the partnership configurations over every phase of the adult literacy intervention. To simplify, these are identified as the planning, delivery and evaluation of the intervention. The overlay denotes the potential importance of partnerships to all aspects of the intervention. Currently health literacy partnerships in Australia involve primarily the meso and micro organisational levels.

It is at the micro organisational level where pedagogy plays its role, and we have outlined some of the key teaching strategies in the findings and discussion section which draw on and build social capital for participants as determined by the changes described in Table 1. In light of the pedagogical strategies outlined earlier, and as a guide to better understanding and developing these teaching strategies linked with social capital outcomes, we conceptualise three interlinked networks where this social capital learning occurs: the learner group, existing networks, and potential new networks (see Figure 2).

\section{Figure 2 Learner networks (here)}

\section{Learner group}

The learner network comprising the teachers/presenters and the students is a new network for all participants and arguably the most important network from the teachers' perspective because it is the one they can most directly influence. It is the network that has learning as its common purpose. Teaching strategies that can lead to social capital outcomes within the learner group include:

Foster relationships between learners and between learners and teachers (i.e. developing bonding ties).

Negotiate the content and the teaching approach with learners.

Devise with students a set of protocols that encourage an open and respectful learning environment.

\section{Existing networks}


All students are members of existing networks, which may include their family, friendship groups, community groups and work, and students may change in their relations and interactions within these networks. Teaching strategies that increase the likelihood of social capital outcomes occurring through the existing networks of the students include:

Ensure the programme/course content is relevant to the everyday lives of the students.

Draw on the students' life experiences.

Encourage a role in the learning environment for other members of the existing networks, such as family members.

\section{Potential new networks}

Social capital outcomes include learners accessing or becoming members of new networks that offer contacts, services, knowledge, and other social, economic and cultural resources that the participants had not previously enjoyed. Becoming members of new networks leads participants to experiencing new sets of norms, values and beliefs which in turn may result in changes to how they perceive themselves (identity resources) and others. Teaching strategies to encourage new networks include:

Arrange for learning experiences to occur in out-of-class contexts that will be useful to the participants.

Set tasks that require learners to interact with networks (organisations, community groups, service providers) they have not yet accessed.

Invite people from potentially useful networks to co-teach or co-participate.

Foster the building of bridging and linking ties.

These three interlinked networks may provide a useful conceptual framework to guide health and adult literacy practitioners in working together to develop bonding, bridging and linking ties for their client/student groups in health literacy partnerships (see Balatti and Black 2011).

\section{Conclusions}

We have claimed in our previous research that to understand and view adult literacy partnerships and pedagogy from a social capital perspective represents a new paradigm (Balatti, Black and Falk 2009). While the various organisational partnerships and pedagogical strategies outlined in our research of themselves may not differ markedly from those traditionally associated with the field of adult literacy, to locate and view them within a conceptual framework comprising social networks is new and potentially of value from a research and practice perspective. In our previous research we identified social capital outcomes from adult literacy courses and linked them with various indicators of socio-economic wellbeing (Balatti, Black, and Falk 2006 ), showing the potential benefits and value to individuals and communities of social capital outcomes. This paper reports on research that went one stage further by focusing on the types of health literacy partnerships that may be needed and some pedagogical strategies within them that are likely to result in social capital outcomes.

In this paper we have also noted the health sector's own burgeoning interest in social capital within a social determinants approach to health and wellbeing. However, as we found in our 
research, combining the work of adult literacy and health professionals in health literacy initiatives in Australia, unlike in some overseas countries, has to date been very limited. While we have suggested from our research findings that these albeit limited health literacy partnerships may have resulted largely at the instigation of adult literacy practitioners, there are nevertheless indications that the health sector is receptive to such partnerships. Australian researchers in health promotion, for example, write about the need for cross-sectoral partnerships to reduce health disparities within a social determinants approach to health (Smith, Keleher, and Fry 2008), and they specifically promote partnerships with adult literacy practitioners (Keleher and Hagger 2007).

What is currently lacking is the broader macro level (Figure 1) collaboration between governments and peak organisations representing health, adult literacy/education, and community groups (see Green, Lo Bianco, and Wyn 2007, 30). Until partnerships at this macro organisational level develop and thus result in policy direction, a sustainable funding base, and research to trial and evaluate health literacy partnerships for their health and wellbeing outcomes, then health literacy partnerships in Australia are likely to remain ad hoc, undeveloped, and with limited local benefits.

\section{References}

Australian National Training Authority (ANTA). 2003. Language, literacy and numeracy in training packages: ANTA think-piece. Brisbane: ANTA.

Allison, J., S. Gorringe, and J. Lacey. 2006. Building learning communities: Partnerships, social capital and VET performance. Adelaide: National Centre for Vocational Education Research.

Australian Bureau of Statistics (ABS). Australian Bureau of Statistics (ABS). 2004. Measuring social capital: An Australian framework and indicators. Information paper, cat. no. 1378.0. Canberra: ABS.

Australian Bureau of Statistics (ABS). 2007. Adult literacy and life skills survey, summary results, Australia. Canberra: ABS.

Australian Bureau of Statistics (ABS). 2008. Health literacy, Australia, 2006. cat. no. 4233.0. Canberra: ABS.

Balatti, J., and I. Falk. 2002. Socioeconomic contributions of adult learning to community: A social capital perspective. Adult Education Quarterly 52: 281-98.

Balatti, J., and S. Black. 2011. Constructing learners as members of networks, in Catts, R., Falk, I. \& Wallace, R. (eds), Vocational learning: Innovative theory and practice, Dordrecht, Springer. pp. 63-76.

Balatti, J., S. Black, and I. Falk. 2006. Reframing adult literacy and numeracy course outcomes: A social capital perspective. Adelaide: National Centre for Vocational Education Research.

Balatti, J., S. Black, and I. Falk. 2009. A new social capital paradigm for adult literacy: Partnerships, policy and pedagogy. Adelaide: National Centre for Vocational Education.

Black, S. 2012. Diabetes literacy: Health and adult literacy practitioners in partnership. Australian Journal of Adult Learning 52: 89-113.

Black, S., and K.Yasukawa. 2010. Time for national renewal: Australian adult literacy and numeracy as 'foundation skills'. Literacy \& Numeracy Studies 18: 43-57.

Black, S., and K.Yasukawa. 2011. Working together: Integrated language, literacy and numeracy support in vocational education and training. Sydney: University of Technology, Sydney. 
Black, S., A. Ndaba, C. Kerr, and B. Doyle. 2012. Methadone, counselling and literacy: A health literacy partnership for Aboriginal clients. Literacy and Numeracy Studies, 20: 45-62.

Booth, R., S. Roy, H.Jenkins, B. Clayton, and S. Sutcliffe. 2005. Workplace training practices in the residential aged care sector. Adelaide: National Centre for Vocational Education Research.

Boyer, K., P. Orpin, and J. Walker. 2010. Partner or perish: Experiences from the field about collaboration for reform. Australian Journal of Primary Health 16: 104-107.

Brough, M., G. Henderson, R. Foster, and H. Douglas. 2007. Social capital and Aboriginal and Torres Strait Islander health - problems and possibilities. In Proceedings social determinants of Aboriginal health workshop, ed. I. Anderson, F. Baum, F, and M. Bentley., 191-201. Adelaide.

Campbell, C. 2001. Social capital and health: Contextualising health promotion within local community networks. In Social capital: Critical perspectives, ed. S. Baron, J. Field, and T. Schuller., 182-96. Oxford: Oxford University Press.

Coleman, J. 1988. Social capital in the creation of human capital. American Journal of Sociology. 94, Supplement S: 95-120.

Coleman, J. 1990. Equality and achievement in education. Boulder: Westview Press.

Courtenay, M., and G. Mawer. 1995. Integrating English language, literacy and numeracy into vocational education and training: A framework. Sydney: TAFE NSW.

Diabetes Australia. 2007. National priorities for turning around the diabetes epidemic 20072008. Canberra: Diabetes Australia.

Diehl, S. 2011. Health literacy education within adult literacy instruction. New Directions for Adult and Continuing Education 130: 29-41.

Falk, I., B. Golding, and J. Balatti, J. 2000. Building communities: ACE, lifelong learning and social capital. Melbourne: Adult Community and Further Education Board.

Field, J., and T. Schuller. 1997. Norms, networks and trust. Adult Learning 9: 17-18.

Figgis, J. 2004. Literate Australia: A whole life approach: Report No.1: Taking literacy to fresh fields, viewed 29 September 2007, <www.acal.edu.au/publications_papers.shtml>.

Gillies, P. 1998. Effectiveness of alliances and partnerships for health promotion. Health Promotion International 13: 99-120.

Granovetter, M. 1973. The strength of weak ties. American Journal of Sociology 78: 1360-80.

Green, J., J. Lo Bianco, and J. Wyn. 2007. Discourses in interaction: The intersection of literacy and health research internationally. Literacy \& Numeracy Studies 15: 19-37.

Hohn, M. 1998. Empowerment health education in adult literacy: A guide for public health and adult literacy practitioners, policy makers and funders. Massachusetts: National Institute for Literacy.

Hartley, R., and J. Horne. 2006. Social and economic benefits of improved adult literacy: Towards a better understanding. Adelaide: National Centre for Vocational Education Research.

Kawachi, I., S. Subramanian, and D. Kim. 2008. Social capital and health: A decade of progress and beyond. Dordrecht: Springer.

Keleher, H., and V. Hagger. 2007. Health literacy in primary health care. Australian Journal of Primary Health Care 13: 24-30.

Keleher, H., and B. Murphy, eds. 2004. Understanding health: A determinants approach. Melbourne: Oxford University Press. 
Kemmis, S., and R. McTaggart. 1988. The action research planner. Geelong: Deakin University.

Kickbusch, I., S. Wait, and D. Maag. 2005. Navigating health: The role of health literacy. London: Alliance for Health and the Future.

Lave, J., and E. Wenger. 1991. Situated learning: Legitimate peripheral participation. New York: Cambridge University Press.

Leenders, R., and Gabbay, S. 1999. CSC: An agenda for the future. In Corporate social capital and liability, ed. R. Leenders.,and S. Gabbay, 483-94. Norwell: Kluwer Academic Publishers.

McKenna, R., and L. Fitzpatrick. 2005. Integrated approaches to teaching adult literacy in Australia: A snapshot of practice in community services. Adelaide: National Centre for Vocational Education Research.

Mattessich, P., M. Murray-Close, and B. Monsey. 2004. Collaboration: What makes it work? Saint Paul, Minnesota: Amherst H. Wilder Foundation.

Nielsen_Bohlman, L., A. Panzar, and D. Kindig, eds. 2004. Health literacy: A prescription to end confusion. Wahington DC: Institute of Medicine.

Nutbeam, D., M. Wise, A. Bauman, E. Harris, and S. Leeder. 1993. Goals and targets for Australia's health in the year 2000 and beyond. Canberra: AGPS.

Nutbeam, D. 1999. Literacies across the lifespan: Health literacy. Literacy \& Numeracy Studies 9: 47-55.

Nutbeam, D. 2008. The evolving concept of health literacy. Social Science \& Medicine 67: 20722078.

OECD/Statistics Canada. 2005. Learning a Living: First results of the adult literacy and life skills survey. Ottawa: Statistics Canada.

Peerson, A., and M. Saunders. 2009. Health literacy revisited: What do we mean and why does it matter? Health Promotion International 24: 285-96.

Portes, A. 1998. Social capital: Its origins and applications in modern sociology. Annual Review of Sociology 24: 1-24

Putnam, R. 1993. Making democracy work. Princeton: Princeton University Press.

Rootman, I., and D. Gordon-El-Bihbety. 2008. A vision for a health literacy Canada: Report of the expert panel on health literacy. Ottawa: Canadian Public Health Association.

Rudd, R. 2002. A maturing partnership, Focus on Basics, vol.5, Issue C. viewed 29 September 2007, www.ncsall.net/?id=771\&pid=247.

Schecter, S., and J. Lynch. 2011. Health learning and adult education: In search of a theory of practice. Adult Education Quarterly 61: 207-224.

Schuller, T., and J. Field. 1998. Social capital, human capital and the learning society. International Journal of Lifelong Education 17: 226-35.

Shohet, L. 2004. Health and literacy: Perspectives. Literacy and Numeracy Studies 13: 65-83.

Sissel, P., and D. Hohn. 1996. Literacy and health communities: Potential partners in practice, New Directions for Adult and Continuing Education 70: 59-71.

Smith, B., H. Keleher, and C. Fry. 2008. Developing values, evidence and advocacy to address the social determinants of health. Health Promotion Journal of Australia 19: 171-172.

St. Clair, R. 2008. Reading, writing and relationships: Human and social capital in family literacy programmes Adult Basic Education and Literacy Journal 2:84-93. 
Stewart, S., G. Tikellis, C. Carrington, K. Walker, and K. O'Dea. 2008. Australia's future 'fat bomb': A report on the long-term consequences of Australia's expanding waistline on cardiovascular disease. Melbourne: Baker Heart Research Institute.

Szreter, S., and M. Woolcock, 2004. Health by association? Social capital, social theory, and the political economy of public health. International Journal of Epidemiology 33: 650-67.

The Tavistock Institute. 2009. Evaluation of the second phase of the skilled for health programme: Final evaluation report. London: The Tavistock Institute.

Tett, L., and K. Maclachlan. 2007. Adult literacy and numeracy, social capital, learner identities and self confidence. Studies in the Education of Adults 39: 150-167.

Wenger, E. 1998. Communities of practice: Learning, meaning, and identity. Cambridge: Cambridge University Press.

Wickert, R., and J. McGuirk. 2005. Integrating literacies: Using partnerships to build literacy capabilities in communities. Adelaide: National Centre for Vocational Education Research.

Wilkinson, R., and M. Marmot, ed. 2003. Social determinants of health: The Solid Facts, $2^{\text {nd }}$ edition. Denmark: World Health Organisation.

World Health Organisation (WHO). 2005. The Bangkok charter for health promotion in a globalised world. Geneva: WHO.

World Health Organisation (WHO). 2008. Closing the gap in a generation: Health equity through action on the social determinants of health, final report, Geneva: WHO/Commission on Social Determinants of Health.

Zarcadoolas, C. 2010. The simplicity complex: Exploring simplified health messages in a complex world. Health Promotion International 26: 338-350. 
Figure 1 Organisational levels for partnerships

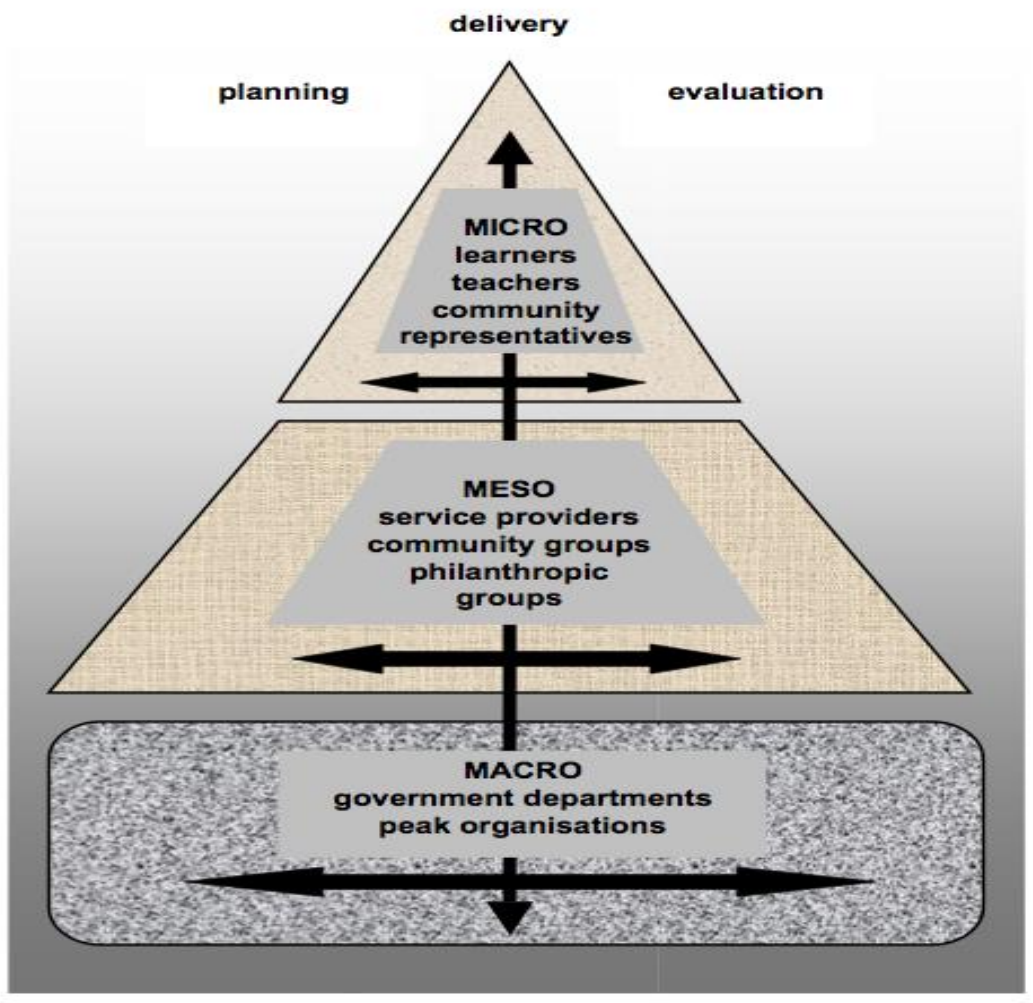




\section{Figure 2 Learner networks}

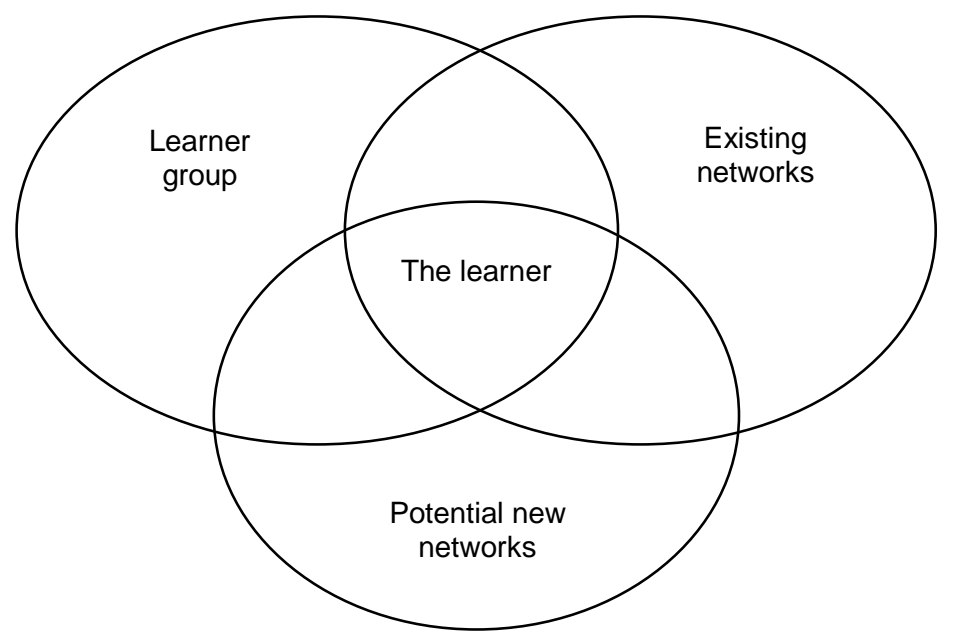

